\title{
Gentamicin-collagen sponge reduces the risk of sternal wound infections after heart surgery: Meta-analysis
}

\author{
Mariusz Kowalewski, MD, ${ }^{\text {a,g }}$ Wojciech Pawliszak, MD, ${ }^{\text {a,b }}$ Katarzyna Zaborowska, RN, \\ Eliano Pio Navarese, MD, PhD, ${ }^{c, g}$ Krzysztof Aleksander Szwed, MD, ${ }^{\mathrm{d}}$ \\ Magdalena Ewa Kowalkowska, MD, ${ }^{e, g}$ Janusz Kowalewski, MD, PhD, ${ }^{\mathrm{f}}$ \\ Alina Borkowska, MD, PhD, ${ }^{\mathrm{d}}$ and Lech Anisimowicz, MD, $\mathrm{PhD}^{\mathrm{a}, \mathrm{b}}$
}

\begin{abstract}
Objectives: Sternal wound infections are serious postoperative complications that increase the length of hospital stay and healthcare costs. The benefit of implantable gentamicin-collagen sponges in reducing sternal wound infections has been questioned in a recent multicenter trial. We aimed to perform a comprehensive metaanalysis of studies assessing the efficacy of implantable gentamicin-collagen sponges in sternal wound infection prevention.
\end{abstract}

Methods: Multiple databases were screened for studies assessing the efficacy of implantable gentamicin-collagen sponges after heart surgery. The primary end point was sternal wound infection, and secondary end points were the occurrence of deep sternal wound infection, superficial sternal wound infection, mediastinitis, and mortality. Randomized controlled trials and observational studies were analyzed separately. By means of meta-regression, we examined the correlation between sternal wound infection and extent to which the bilateral internal thoracic artery was harvested.

Results: A total of 14 studies $(\mathrm{N}=22,135$, among them 4 randomized controlled trials $[\mathrm{N}=4672]$ ) were included in the analysis. Implantable gentamicin-collagen sponges significantly reduced the risk of sternal wound infection by approximately $40 \%$ when compared with control (risk ratio [RR], $0.61 ; 95 \%$ confidence interval [CI], 0.39-0.98; $P=.04$ for randomized controlled trials and RR, 0.61; 95\% CI, $0.42-0.89 ; P=.01$ for observational studies). A similar, significant benefit was demonstrated for deep sternal wound infection (RR, 0.60; 95\% CI, 0.42-0.88; $P=.008)$ and superficial sternal wound infection (RR, 0.60; 95\% CI, 0.43$0.83 ; P=.002)$. The overall analysis revealed a reduced risk of mediastinitis (RR, $0.64 ; 95 \%$ CI, 0.45-0.91; $P=.01$ ). The risk of death was unchanged. A significant positive linear correlation $(P=.05)$ was found between the log RR of sternal wound infection and the percentage of patients receiving bilateral internal thoracic artery grafts.

Conclusions: Implantable gentamicin-collagen sponges significantly reduce the risk of sternal wound infection after cardiac surgery, with evidence consistent in randomized and observational-level data. However, the extent of this benefit might be attenuated in patients receiving bilateral internal thoracic artery grafts. (J Thorac Cardiovasc Surg 2015;149:1631-40)

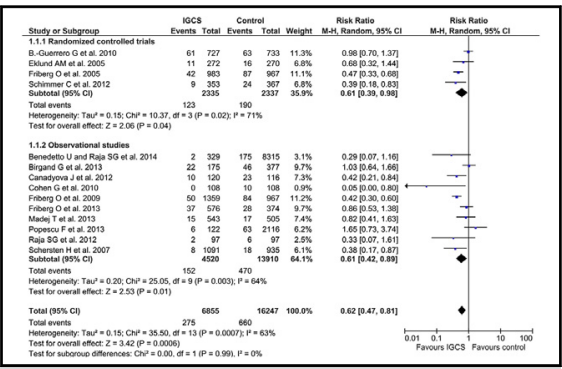

Efficacy of implantable gentamicin-collagen sponge in preventing sternal wound infections.

\section{Central Message}

Implantable gentamicin-collagen sponge significantly reduces the risk of sternal wound infection after cardiac surgery by nearly $40 \%$ with evidence highly consistent in randomized- and observational-level data. However, the extent of this benefit might be attenuated in patients receiving bilateral internal thoracic artery grafts.

\section{Perspective}

Recent randomized study introduced substantia uncertainty regarding the efficacy of implantable gentamicin-collagen sponge in sternal wound infections prophylaxis. Present study confirms and corroborates in a systematic fashion the findings from the previous studies showing statistically significant reduction of sternal wound infections in patients in whom gentamicin sponge was implanted. Lower benefit conferred by the gentamicin sponge in patients receiving bilateral internal thoracic artery grafts should direct the surgeon's attention to these patients in particular because other potentially preventive measures must be undertaken in this population.

See Editorial Commentary page 1641.

\footnotetext{
From the Department of Cardiac Surgery, ${ }^{a}$ Dr Antoni Jurasz Memorial University Hospital, Bydgoszcz, Poland; Cardiac Surgery, ${ }^{\mathrm{b}}$ Nicolaus Copernicus University in Toruń, Collegium Medicum, Bydgoszcz, Poland; Division of Cardiology, Pulmonology and Vascular Medicine, ${ }^{c}$ Department of Internal Medicine, Heinrich-Heine-University, Düsseldorf, Germany; Department of Clinical Neuropsychology, ${ }^{\mathrm{d}}$ Nicolaus Copernicus University in Torun, Collegium Medicum, Bydgoszcz, Poland; Department and Clinic of Obstetrics, Gynecology, and Oncological Gynecology, ${ }^{e}$ Collegium Medicum, Bydgoszcz, Poland; Lung Cancer and Thoracic Surgery Department, ${ }^{f}$ Collegium Medicum in Bydgoszcz, Nicolaus Copernicus University, Toruń, Poland; and Systematic Investigation
}

and Research on Interventions and Outcomes, ${ }^{\mathrm{g}}$ Medicine Research Network, Poland.

M.K. and W.P. equally contributed to the present article.

Received for publication Nov 22, 2014; revisions received Jan 13, 2015; accepted for publication Jan 20, 2015; available ahead of print Feb 19, 2015

Address for reprints: Mariusz Kowalewski, MD, Department of Cardiac Surgery, Dr Antoni Jurasz Memorial University Hospital in Bydgoszcz, Maria Curie Sklosowska Str 9, 85-094 Bydgoszcz, Poland (E-mail: kowalewkimariusz@gazeta.pl). $0022-5223 / \$ 36.00$

Copyright (C) 2015 by The American Association for Thoracic Surgery http://dx.doi.org/10.1016/j.jtcvs.2015.01.034 


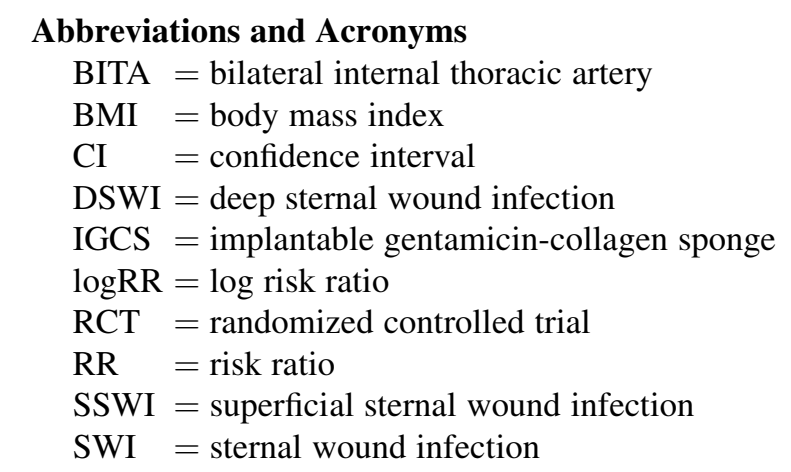

Supplemental material is available online.

Routine intravenous antibiotic prophylaxis initiated before cardiothoracic surgery has been consistently shown to reduce the postoperative rates of infections and in turn associated morbidity and mortality. ${ }^{1}$ Sternal wound infections (SWIs) are serious postoperative complications increasing both length of hospital stay and healthcare costs. Several early randomized and observational studies demonstrated implantable gentamicin-collagen sponges (IGCSs) to further reduce (by $33 \%-62 \%$ ) the infectious complications compared with intravenous (IV) prophylaxis alone when inserted between sternal halves immediately before closure of the mediastinum..$^{2-5}$ These implants deliver high concentrations of gentamicin locally within the wound, therefore preventing the systemic adverse effects of such high regimens and at the same time lowering the risk of acquired bacterial resistance to antibiotics. ${ }^{6}$ On the other hand, the recent SWIPE- $1^{7}$ trial questioned those results, showing no extra benefit of IGCS among US patients at high baseline risk, including diabetes, body mass index (BMI) $>30 \mathrm{~kg} / \mathrm{m}^{2}$, or both. The study showed no difference between IGCS and control groups for the outcomes of superficial SWI (SSWI), deep SWI (DSWI), and rehospitalization for wound infection at 90-day follow-up. Driven by the conflicting results and limited number of randomized studies, we aimed to perform an updated and comprehensive metaanalysis of randomized controlled trials (RCTs) with an addition of observational data to further corroborate the obtained results. In addition, for the first time, we try to explore the efficacy of the IGCS in the setting of bilateral internal thoracic artery (BITA) harvest.

\section{MATERIALS AND METHODS}

\section{Data Sources and Search Strategy}

Established methods were used in compliance with the Preferred Reporting Items for Systematic Reviews and Meta-Analyses statement for reporting systematic reviews and meta-analyses in health care interventions. ${ }^{8}$ PubMed, EMBASE, CINAHL, Scopus, the Web of Science, the Cochrane Register of Controlled Clinical Trials (CENTRAL), and Congress proceedings from major cardiothoracic and cardiothoracic societies meetings were screened for randomized and observational studies comparing the efficacy of the IGCS in prophylaxis of SWI after cardiac surgery with placebo or no intervention. Search terms were gentamicin collagen sponge, gentamicin implant, gentamicin sponge, cardiac surgery, heart surgery, DSWI, SSWI, and mediastinitis. No language, publication date, or publication status restriction was imposed. Both blinded and open-label trials were considered eligible. The most updated or inclusive data for each study were used for abstraction. References of original and review articles were cross-checked.

\section{Selection Criteria and Quality Assessment}

Citations were screened at title/abstract level and retrieved as full reports if they fulfilled the inclusion criteria: (1) human studies; (2) RCTs or observational studies with control group; and (3) prespecified outcome of SWI reported. Two independent reviewers (M.K. and W.P.) selected the studies for the inclusion and extracted studies and patient characteristics of interest and relevant outcomes; divergences were resolved by consensus after discussion with a third reviewer (L.A.). Three authors (M.K., W.P., and M.E.K.) independently assessed the trials' eligibility and risk of bias. The bias risk for randomized studies was assessed using the components recommended by the Cochrane Collaboration, that is, random sequence generation and random allocation; allocation concealment; blinding of participants, personnel, and outcome assessors; incomplete outcome data; selective outcome reporting; and other sources of bias. ${ }^{9}$ The quality of observational studies was appraised with the Newcastle-Ottawa Scale, a tool used for assessing the bias (the selection of the study groups, the comparability of the groups, and the ascertainment of the exposure or outcome of interest) in case-control and cohort studies included in a systematic review or meta-analyses. ${ }^{10}$

\section{Outcome Measures}

The primary end point was the occurrence of SWI after cardiac surgery. Secondary end points were the occurrence of DSWI, SSWI, mediastinitis, and mortality. Definitions for the type, degree, and depth of the infection were applied as per study protocol.

\section{Statistical Analysis}

Data were analyzed according to the intention-to-treat principle. Randomized and observational studies were assessed separately. Risk ratios (RRs) and 95\% confidence intervals (CIs) were used as summary statistics. Heterogeneity was assessed by the Cochran $Q$ test. ${ }^{11}$ The statistical inconsistency test was $\mathrm{I}^{2}=\left[\left(\mathrm{Q}_{-} \mathrm{df}\right) / \mathrm{Q}\right] \times 100 \%$, where $\mathrm{Q}$ is the chi-square statistic and $\mathrm{df}$ is its degrees of freedom. Thresholds for the interpretation of $\mathrm{I}^{2}$ for low, moderate, and considerable degree of heterogeneity were values of $25 \%, 50 \%$, and $75 \%$, respectively. ${ }^{12}$ Pooled RRs were calculated using a fixed-effects model for a randomized trials subset in case of low heterogeneity. Pooled RRs from observational studies were calculated using random-effects model with the Mantel-Haenszel method as the most conservative approach. Potential publication bias was examined for the primary end point constructing a "funnel plot" in which the standard error of the log risk ratio $(\log R R)$ was plotted against the RR. The asymmetry of the plot was estimated both visually and by a linear regression approach. Random-effects meta-regression analyses accounting for within- and between-study variations were conducted to evaluate linear correlations between the occurrence of any surgical site infection and the percentage of patients in each study receiving BITA and single internal thoracic artery (SITA) grafts, with the sample size as weight. ${ }^{13}$ Finally, we addressed the influence of each study and potential publication bias by testing whether deleting each study in turn would have significantly changed the pooled results of the meta-analysis for the 


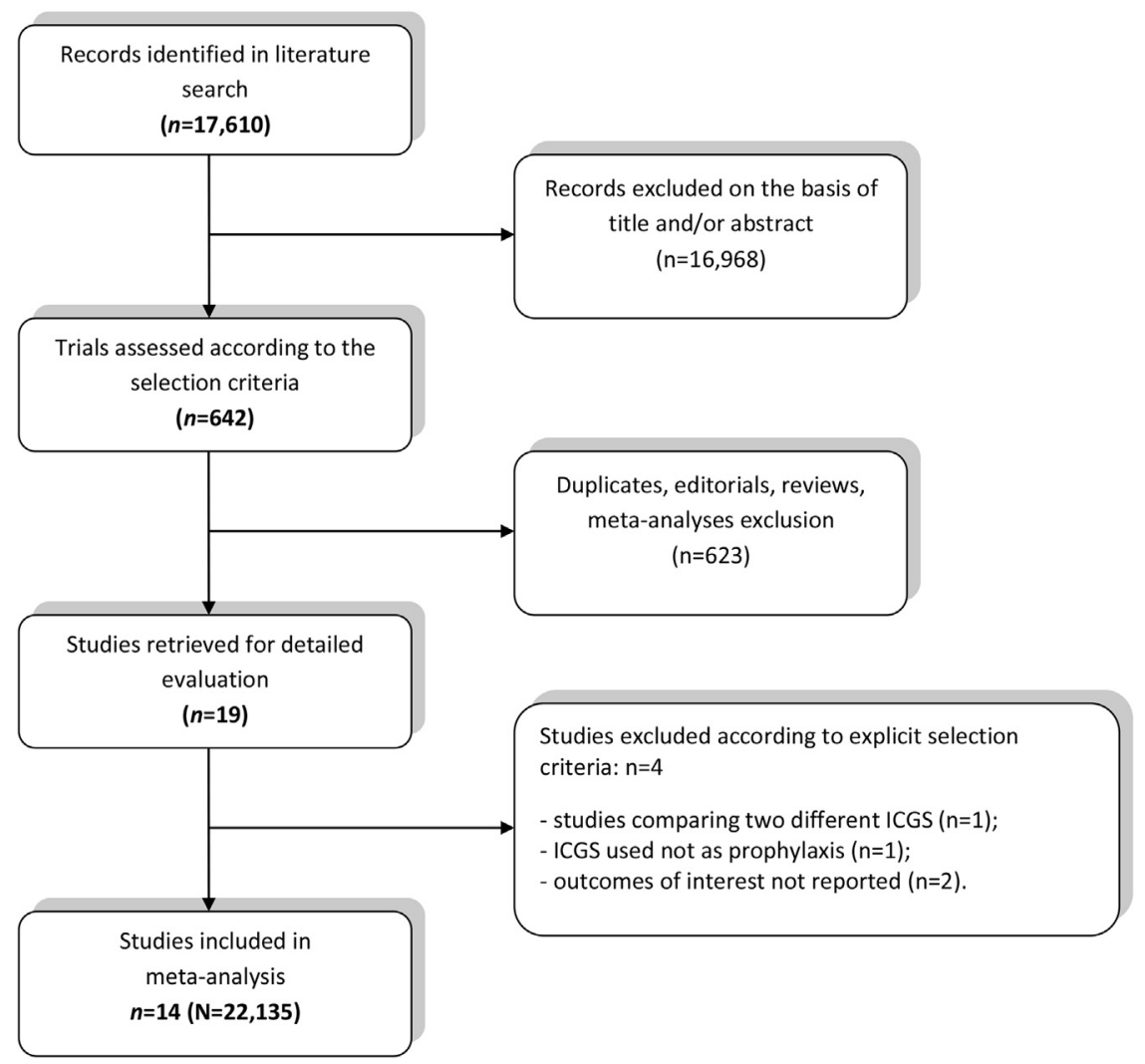

FIGURE 1. Flow diagram of the review process according to the Preferred Reporting Items for Systematic Reviews and Meta-Analyses statement. Total number of patients is reduced by $\mathrm{N}=967$ because of the exact control group in 2 studies. ${ }^{3,5}$ ICGS, Implantable gentamicin-collagen sponge.

primary end point. Likewise, prespecified sensitivity analyses were also performed after exclusion of studies with high risk of bias, studies available as abstracts only, and studies in which a non-Food and Drug Administration-approved gentamicin sponge was used. To better quantify the contribution of proper, manufacturer-advised sponge placement, the analysis was repeated after exclusion of 4 studies reporting the IGCS to be premoistened in normal saline before implantation. Review Manager 5.1 (The Nordic Cochrane Center, Købehvn, Denmark) and Comprehensive Meta-Analysis, version 2 (Biostat, Englewood, NJ) were used for statistical computations. $P$ values are reported as 2 -sided.

\section{RESULTS}

The Preferred Reporting Items for Systematic Reviews and Meta-Analyses flow chart, describing the process of publication screening and the reasons for exclusion, is shown in Figure 1. Of 642 potentially relevant reports that were retrieved for scrutiny, 623 were excluded during secondary screening. The remaining 19 underwent thorough assessment based on prespecified eligibility criteria. One study was excluded because 2 different gentamicin sponges (equine and bovine collagen matrix) were compared, ${ }^{14}$ and another was excluded because IGCS was given as an addition to intervention for deep sternal wound complications ${ }^{15}$ and not as a prophylaxis. Another 2 studies did not report the outcomes of interest.
A total of 14 studies $^{2-7,16-23}(\mathrm{~N}=22,135$; among them 4 RCTs $[\mathrm{N}=4672]$ ) were eventually included for data abstraction and entered the analysis. All published studies were retrieved as full texts. Congress proceedings abstracts were available as separate reports. The characteristics of included studies stratified by study design are listed in Table 1.

Among the RCTs, only 1 was multicenter, ${ }^{7} 1$ was 2 -center, ${ }^{3}$ and 2 were conducted in single institutions. ${ }^{2,16}$ The study by Schimmer and colleagues ${ }^{16}$ was the only one to use a placebo-impregnated sponge, therefore attenuating the allocation concealment bias. Eleven observational studies $(\mathrm{N}=18,430)$ entered the analysis. ${ }^{4-6,16-23}$ Study characteristics are listed in Table 1. Three studies were available as abstracts only. ${ }^{20-22}$ Potential sources of bias according to Newcastle-Ottawa Scale are described in Table E1.

\section{Sternal Wound Infection}

Randomized controlled trials. Four studies $(\mathrm{N}=4672)$ were included in the analysis of SWI (Figure 2, $A$ ). The IGCS-based intervention was associated with a significant, approximately $40 \%$ risk reduction when compared with 
TABLE 1. Characteristics of included studies

\begin{tabular}{|c|c|c|c|c|}
\hline \multirow[b]{2}{*}{ Study } & \multicolumn{2}{|c|}{ No. of patients } & \multicolumn{2}{|c|}{ Procedural characteristics } \\
\hline & IGCS & Control & Gentamicin sponge & Type of surgery \\
\hline \multicolumn{5}{|l|}{ RCTs } \\
\hline Bennett-Guerrero and colleagues, $2010^{7}$ & 727 & 733 & $\begin{array}{l}\text { Collatamp (EUSA } \\
\text { Pharma, Oxford, England)* }\end{array}$ & $\begin{array}{l}\text { Cardiac surgery via median sternotomy and at } \\
\text { high risk for SWI }\end{array}$ \\
\hline Eklund and colleagues, $2005^{2}$ & 272 & 270 & Collatamp & Elective on-pump CABG via median sternotomy \\
\hline Friberg and colleagues, $2005^{3}$ & 983 & 967 & Collatamp & $\begin{array}{l}\text { Cardiac surgery via median sternotomy } \\
\text { including surgery on the thoracic aorta }\end{array}$ \\
\hline Schimmer and colleagues, $2012^{16}$ & 353 & 367 & $\begin{array}{l}\text { GENTA-COLL (RESORBA, } \\
\text { Nuremberg, Germany) }\end{array}$ & $\begin{array}{l}\text { Cardiac surgery via median sternotomy } \\
\text { including surgery on the thoracic aorta }\end{array}$ \\
\hline \multicolumn{5}{|l|}{ Observational studies } \\
\hline Benedetto and Raja, $2014^{17}$ & 329 & 8315 & Collatamp & Cardiac surgery via median sternotomy \\
\hline Birgand et and colleagues, $2013^{18}$ & 175 & 377 & Syntacoll & $\begin{array}{l}\text { Cardiac surgery via median sternotomy; } \\
\text { BITA harvest }\end{array}$ \\
\hline Čanádyová and colleagues, $2012^{19}$ & 120 & 116 & Collatamp & $\begin{array}{l}\text { Cardiac surgery via median sternotomy } \\
\text { including surgery on the thoracic aorta; } \\
\text { excluding heart transplantations }\end{array}$ \\
\hline Cohen and colleagues, $2010^{20}$ & 108 & 108 & Collatamp & Cardiac surgery via median sternotomy \\
\hline Friberg and colleagues, $2009^{5}$ & 1359 & $967 \dagger$ & Collatamp & $\begin{array}{l}\text { Cardiac surgery via median sternotomy } \\
\text { including surgery on the thoracic aorta }\end{array}$ \\
\hline Friberg and Bodin, $2013^{21}$ & 576 & 374 & Collatamp & $\begin{array}{l}\text { Cardiac surgery via median sternotomy } \\
\text { including surgery on the thoracic aorta }\end{array}$ \\
\hline Madej and colleagues, $2013^{22}$ & 543 & 505 & GENTA-COLL & Elective cardiac surgery via median sternotomy \\
\hline Popescu and colleagues, $2013^{23}$ & 122 & 2116 & Collatamp & Cardiac surgery via median sternotomy \\
\hline Raja, $2012^{6}$ & 97 & 97 & Collatamp & Cardiac surgery via median sternotomy \\
\hline Schersten, $2007^{4}$ & 1091 & 935 & Collatamp & Cardiac surgery via median sternotomy \\
\hline
\end{tabular}

BITA, Bilateral internal thoracic artery; CoNS, coagulase-negative staphylococci; IGCS, implantable gentamicin collagen sponge; IV, intravenous; $M R S A$, methicillin-resistant Staphylococcus aureus; $N R$, not reported; $R C T$, randomized controlled trial; SITA, single internal thoracic artery; $D S W I$, deep sternal wound infection; $C A B G$, Coronary artery bypass grafting. *Available under various names. $\nmid$ Represents the control group from Friberg and colleagues. ${ }^{3}$ 
TABLE 1. Continued

\begin{tabular}{|c|c|c|c|c|c|}
\hline \multicolumn{3}{|c|}{ Procedural characteristics } & \multirow[b]{2}{*}{$\begin{array}{l}\text { Most commonly } \\
\text { isolated bacteria }\end{array}$} & \multirow[b]{2}{*}{$\begin{array}{c}\text { Primary } \\
\text { end points }\end{array}$} & \multirow[b]{2}{*}{ Follow-up } \\
\hline $\begin{array}{c}\text { Background } \\
\text { antibiotic prophylaxis }\end{array}$ & $\begin{array}{l}\text { IGCS placement and } \\
\text { closure technique }\end{array}$ & $\begin{array}{l}\text { BITA }(\%) \\
\text { SITA }(\%)\end{array}$ & & & \\
\hline IV antibiotics & $\begin{array}{l}\text { Premoistened in saline; placement } \\
\text { along the full length of the } \\
\text { sternum }\end{array}$ & $3.2 \% ; 79.4 \%$ & $\begin{array}{l}\text { Staphylococcus aureus; } \\
\text { CoNS; Enterobacteriaceae }\end{array}$ & SWI & $\begin{array}{l}\text { 90th day } \\
\text { postoperatively }\end{array}$ \\
\hline $\begin{array}{l}\text { IV cefuroxime; IV } \\
\text { cefuroxime }+ \\
\text { vancomycin }\end{array}$ & Retrosternal placement & $10 \% ; 96 \%$ & CoNS; $S$ aureus & SWI & $\begin{array}{l}\text { 90th day } \\
\text { postoperatively }\end{array}$ \\
\hline IV isoxazolyl-penicillin & $\begin{array}{l}\text { Placement along the full length } \\
\text { of the sternum; also } \\
\text { retrosternally at proximal and } \\
\text { distal ends; } 6-8 \text { sternal wires }\end{array}$ & $0.9 \% ; 71.9 \%$ & CoNS; $S$ aureus & SWI & $\begin{array}{l}\text { 60th day } \\
\text { postoperatively }\end{array}$ \\
\hline IV cefuroxime & $\begin{array}{l}\text { Retrosternal placement; trans-/ } \\
\text { peristernal, figure of } 8, \text { or band } \\
\text { cerclages sternal wiring }\end{array}$ & NR & $\begin{array}{l}\text { CoNS; } \mathrm{G}(-) \text { bacteria; } \\
\quad \text { Propionibacterium acnes; } \\
\quad \text { S aureus }\end{array}$ & DSWI & $\begin{array}{l}\text { 30th day } \\
\text { postoperatively }\end{array}$ \\
\hline \multicolumn{6}{|l|}{ Observational studies } \\
\hline NR & $\begin{array}{l}\text { Placement along the full length of } \\
\text { the sternum }\end{array}$ & 18.4 & NR & DSWI & Perioperative \\
\hline $\begin{array}{l}\text { IV cefamandole; } \\
\text { IV vancomycin or } \\
\text { gentamicin in } \\
\text { MRSA carriers } \\
\text { or in case of } \\
\text { allergy }\end{array}$ & $\begin{array}{l}\text { Premoistened in saline; placement } \\
\text { along the full length of the } \\
\text { sternum }\end{array}$ & 92.6 & $\begin{array}{l}\text { Enterobacteriaceae; CoNS; } \\
\quad \text { S aureus; Pseudomonas } \\
\quad \text { aeruginosa }\end{array}$ & DSWI & $\begin{array}{l}\text { 60th day } \\
\text { postoperatively }\end{array}$ \\
\hline IV cefazolin & $\begin{array}{l}\text { Premoistened in saline; placement } \\
\text { of single layer along the full } \\
\text { length of the sternum, also } \\
\text { retrosternally at proximal and } \\
\text { distal ends; } 8-10 \text { sternal wires }\end{array}$ & NR & $\begin{array}{c}\text { S aureus; } \text { CoNS; Escherichia } \\
\text { coli } \text { Enterobacteriaceae; } \\
\text { Morganella morganii; } \\
\text { Corynebacterium species }\end{array}$ & $\begin{array}{l}\text { Surgical site } \\
\text { infection }\end{array}$ & $\begin{array}{l}\text { 90th day } \\
\text { postoperatively }\end{array}$ \\
\hline Standard of care & $\mathrm{NR}$ & NR & $\mathrm{NR}$ & SWI & perioperative \\
\hline IV isoxazolyl-penicillin & $\begin{array}{l}\text { Placement along the full length of } \\
\text { the sternum; also retrosternally } \\
\text { at proximal and distal ends; } \\
>7 \text { sternal wires }\end{array}$ & $0.1 \% ; 56 \%$ & $\begin{array}{l}\text { CoNS; } S \text { aureus; } \mathrm{G}(-) \\
\quad \text { bacteria; } \\
\text { Propionibacterium acnes }\end{array}$ & SWI & $\begin{array}{l}\text { 60th day } \\
\text { postoperatively }\end{array}$ \\
\hline $\begin{array}{l}\text { IV cloxacillin; } \\
\text { IV clindamycin in } \\
\text { case of allergy }\end{array}$ & $\begin{array}{l}\text { Placement along the full length of } \\
\text { the sternum; use of } 2 \text { sponges } \\
\text { was recommended. Average } \\
\mathrm{n} \text { of sternal wires }=7.8\end{array}$ & $0.2 \% ; 43.6 \%$ & CoNS & SWI & $\begin{array}{l}\text { 60th day } \\
\text { postoperatively }\end{array}$ \\
\hline Standard of care & Retrosternal placement & NR & $S$ aureus; $S$ epidermidis & $\begin{array}{l}\text { Freedom from } \\
\text { mediastinitis }\end{array}$ & $\begin{array}{l}\text { 30th day } \\
\text { postoperatively }\end{array}$ \\
\hline IV antibiotics & $\mathrm{NR}$ & NR & NR & SWI & Perioperative \\
\hline Standard of care & $\begin{array}{l}\text { Retrosternal placement; trans-/ } \\
\text { peristernal wires }\end{array}$ & $36.4 \%$ & NR & SWI & $\begin{array}{l}\text { 42nd day } \\
\text { postoperatively }\end{array}$ \\
\hline IV isoxazolyl-penicillin & $\begin{array}{l}\text { Placement along the full length of } \\
\text { the sternum; }>7 \text { sternal wires } \\
\text { (at least } 2 \text { in the xiphoid region) }\end{array}$ & NR & $\begin{array}{l}\text { CoNS; } S \text { aureus; } \\
\text { Enterobacteriaceae; } \\
\text { Acinetobacter sp. } \\
\text { Propionibacterium acnes }\end{array}$ & Mediastinitis & Perioperative \\
\hline
\end{tabular}


control (RR, $0.61 ; 95 \%$ CI, 0.39-0.98; $P=.04 ; \mathrm{I}^{2}=71 \%$ ); corresponding event rates were $5.27 \%(123 / 2335)$ versus $8.13 \%(190 / 2337)$ for IGCS and the control group, respectively.

Observational studies. Ten observational studies entered the analysis with $\mathrm{N}=18,430$ patients (Figure 2, $A$ ). SWIs occurred in 152 of 4520 ICGS-treated patients and 470 of 13,910 controls. Prophylaxis with IGCS was associated with a 39\% reduced risk of SWI compared with the control group (RR, $0.61 ; 95 \% \mathrm{CI}, 0.42-0.89 ; P=.01$; $\left.\mathrm{I}^{2}=64 \%\right)$.

Overall. Pooled together, randomized and observational studies demonstrated the gentamicin-collagen sponge to be associated with a significant $38 \%$ reduced risk of SWI (RR, 0.62; 95\% CI, 0.47-0.81; $P<.001 ; \mathrm{I}^{2}=63 \%$ ) (Figure 2, A). Analysis of differences between RCTs and observational studies showed no signs of inconsistency: test for subgroup differences: chi-square $=0.00 ; P=.99$; $\mathrm{I}^{2}=0 \%$. Regression of logRR against the percentage of patients receiving BITA grafts demonstrated a significant positive correlation $\left(P_{\text {slope }}=.05\right)$ between the risk of SWI and the extent to which BITA harvest was performed (Figure 2, B). Analysis regressing the percentage of single ITA against $\operatorname{logRR}$ revealed a borderline significant negative correlation $\left(P_{\text {slope }}=.06\right)$ (Figure $\left.2, C\right)$.

\section{Deep Sternal Wound Infection}

Randomized controlled trials. Data on DSWI were available from 4 RCTs; gentamicin sponge prophylaxis reduced the risk of DSWI by $40 \%$ compared with the control group (RR, 0.60; 95\% CI, 0.42-0.88; $P=.008$; $\mathrm{I}^{2}=19 \%$ ); the corresponding event rates were 43 of 2335 IGCS-treated patients $(1.84 \%)$ and 71 of 2337 controls (3.04\%) (Figure 3, A).

Observational studies. Four observational studies reported on the incidence of DSWI with $\mathrm{N}=11,716$ patients. A nonsignificant risk reduction was observed with IGCS when compared with the control group (RR, $0.60 ; 95 \%$ CI, $0.32-1.13 ; P=.12 ; \mathrm{I}^{2}=56 \%$ ) (Figure 3, A).

Overall. In the overall analysis, gentamicin sponge prophylaxis demonstrated a $38 \%$ risk reduction compared with the control group (RR, 0.62; 95\% CI, 0.44-0.87; $P=.006 ; \mathrm{I}^{2}=34 \%$ ) (Figure $3, A$ ). Analysis of differences between RCTs and observational studies showed no signs of inconsistency: test for subgroup differences: chi-square $=0.00 ; P=.96 ; \mathrm{I}^{2}=0 \%$. Regression of $\operatorname{logRR}$ against the percentage of patients receiving BITA grafts demonstrated a significant positive correlation $\left(P_{\text {slope }}=.05\right)$ between the risk of DSWI and the extent to which BITA harvest was performed (Figure 3,B). Analysis regressing the percentage of single ITA against $\operatorname{logRR}$ revealed a significant negative correlation $\left(P_{\text {slope }}=.05\right)($ Figure $3, C)$.

\section{Superficial Sternal Wound Infection}

Randomized controlled trials. Four RCTs $(\mathrm{N}=4672$ patients) reported SSWI incidence (80/2335 [3.43\%] vs $119 / 2337 \quad[5.09 \%] ; \quad R R, \quad 0.65 ; \quad 95 \%$ CI, $0.34-1.25$; $P=.20 ; \mathrm{I}^{2}=76 \%$ ) (Figure 4, $A$ ).

Observational studies. In 5 observational studies ( $\mathrm{N}=3922$ patients), data on the incidence of SSWI were available; a significant $45 \%$ risk reduction was observed with IGCS when compared with the control group (RR, $0.55 ; 95 \%$ CI, $0.36-0.86 ; P=.008 ; \mathrm{I}^{2}=66 \%$ ); event rates were 129 of $2260(5.71 \%)$ and 185 of $1662(11.13 \%)$, respectively (Figure 4, $A$ ).

Overall. Pooled together (9 studies), gentamicin sponge prophylaxis demonstrated a significant, $40 \%$ risk reduction compared with the control group (RR, 0.60; 95\% CI, 0.43-0.83; $P=.002 ; \mathrm{I}^{2}=66 \%$ ) (Figure 4, A). No signs of inconsistency were found for the comparison between observational and randomized studies; test for subgroup differences: chi-square $=0.15 ; P=.70$; $\mathrm{I}^{2}=0 \%$. No correlations between the risk of SSWI and the extent to which both BITA and SITA harvest was performed were found by meta-regressions (Figure 4, $B$ and $C$, respectively).

\section{Mediastinitis}

Randomized controlled trials. Three RCTs $(\mathrm{N}=3212$ patients) were available for inclusion in the analysis of mediastinitis; event rates were 18 of $1608(1.12 \%)$ versus 33 of $1604(2.06 \%)$ (RR, 0.50; 95\% CI, 0.19-1.33; $P=.16 ; \mathrm{I}^{2}=51 \%$ ) (Figure E1).

Observational studies. Six observational studies ( $\mathrm{N}=7096$ patients) contributed to the analysis of mediastinitis; a significant $33 \%$ risk reduction was observed with IGCS when compared with the control group (RR, 0.67; 95\% CI, 0.45-0.99; $P=.04 ; \mathrm{I}^{2}=6 \%$ ); event rates were 46 of $3841(1.20 \%)$ and 67 of $3255(2.06 \%)$, respectively (Figure E1).

Overall. In total, 9 studies were included; gentamicin sponge prophylaxis demonstrated a significant, $36 \%$ risk reduction compared with the control group (RR, 0.64; 95\% CI, 0.45-0.91; $P=.01 ; \mathrm{I}^{2}=16 \%$ ) (Figure E1). Observational studies were found statistically consistent with RCTs; test for subgroup differences (chi-square $=0.29 ; P=.59 ; \mathrm{I}^{2}=0 \%$ ).

\section{Mortality}

Six studies contributed to the analysis of mortality; no differences between the IGCS-based prophylaxis and the control group were found in both randomized (RR, 0.87; 95\% CI, 0.55-1.38; $P=.55 ; \mathrm{I}^{2}=0 \%$ ) and observational studies (RR, 0.97; 95\% CI, 0.33-2.84; $P=.96 ; \mathrm{I}^{2}=0 \%$ ), with findings consistent between these 2 subgroups (chi-square $=0.05 ; P=.83 ; \mathrm{I}^{2}=0 \%$ ) (Figure E2). 

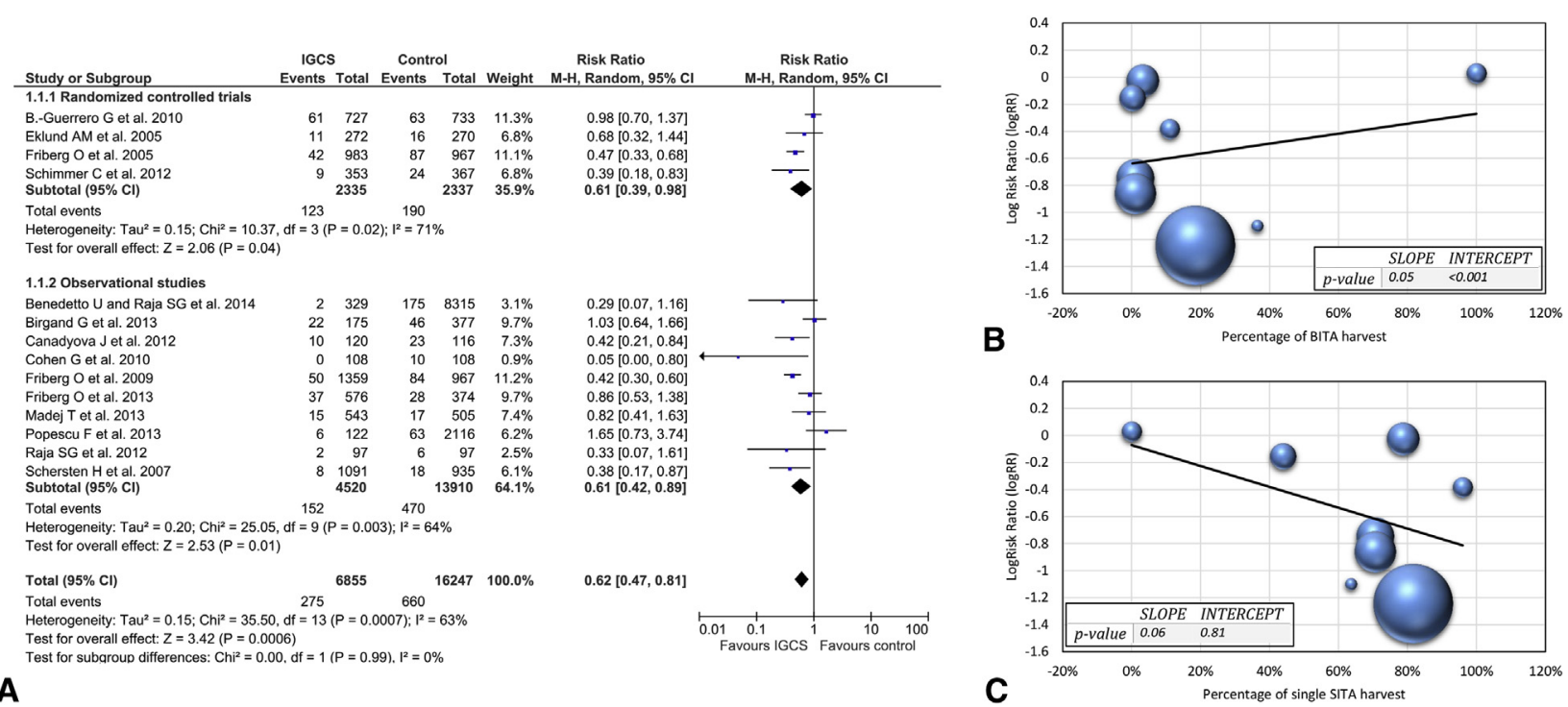

A

FIGURE 2. A, Summary analysis of primary end point SWI. RRs and $95 \%$ CIs. Size of squares is proportional to the statistical weight of each trial. Diamonds represent RR point estimates; horizontal lines represent CIs for given point estimate; positioning of both diamonds and squares (along with CIs) beyond the vertical line (unit value) suggests significant outcome. Meta-regression analysis of the $\operatorname{logRR}$ of primary end point on the percentage of patients receiving BITA (B) and SITA (C) grafts. Size of circles corresponds to the number of patients in each study. BITA, Bilateral internal thoracic artery; $C I$, confidence interval; $d f$, degrees of freedom; IGCS, implantable gentamicin-collagen sponge; $M-H$, Mantel-Haenszel; SITA, single internal thoracic artery.

\section{Sensitivity Analyses}

Sensitivity analyses performed by removing each of the studies one at a time and repeating the calculations did not alter the direction or magnitude of the effect (Figure E3). The estimates did not change after exclusion of studies with a high risk of bias, studies available as abstract only, and studies in which other than Food and Drug Administration-approved Collatamp (EUSA Pharma, Oxford, England) was used. The results also remained consistent when we excluded studies in which gentamicin sponge was premoistened quickly in saline before implantation.

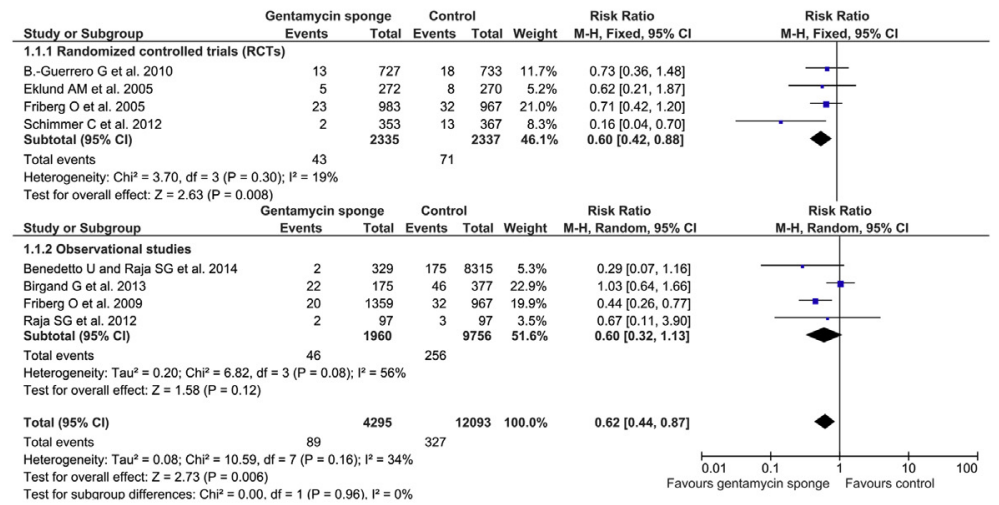

A
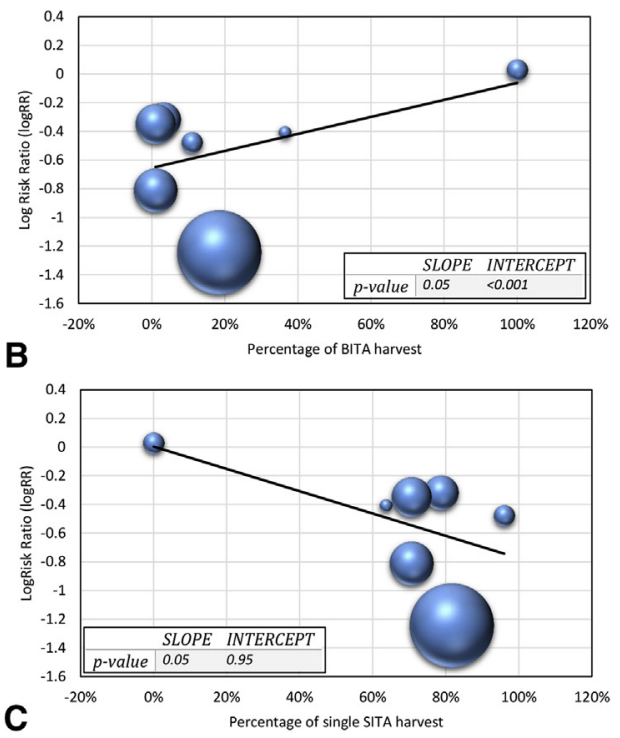

FIGURE 3. A, Summary analysis of DSWI. RRs and 95\% CIs. Size of squares is proportional to the statistical weight of each trial. Diamonds represent RR point estimates; horizontal lines represent CIs for given point estimate; positioning of both diamonds and squares (along with CIs) beyond the vertical line (unit value) suggests significant outcome. Meta-regression analysis of the $\operatorname{logRR}$ of DSWI on the percentage of patients receiving BITA (B) and SITA (C) grafts. Size of circles corresponds to the number of patients in each study. BITA, Bilateral internal thoracic artery; $C I$, confidence interval; $d f$, degrees of freedom; $M-H$, Mantel-Haenszel; SITA, single internal thoracic artery. 

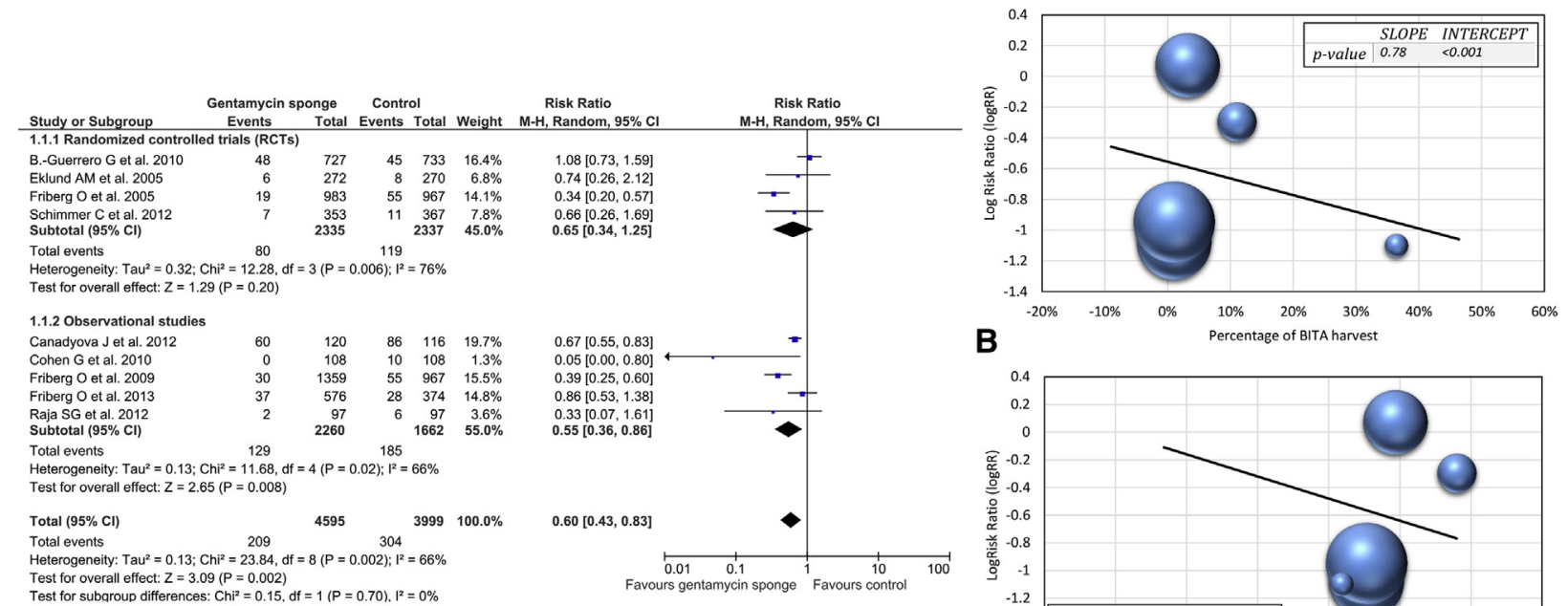

B

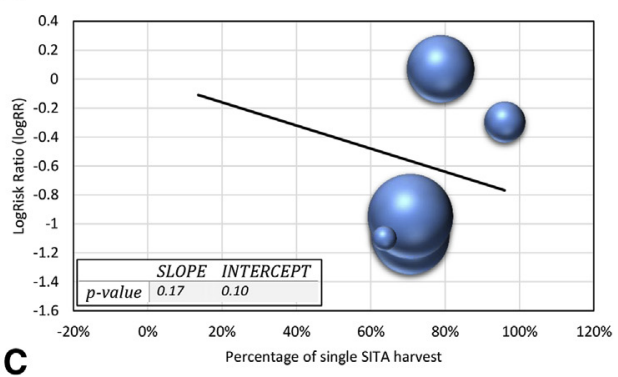

FIGURE 4. A, Summary analysis of SSWI. RRs and 95\% CIs. Size of squares is proportional to the statistical weight of each trial. Diamonds represent RR point estimates; horizontal lines represent CIs for given point estimate; positioning of both diamonds and squares (along with CIs) beyond the vertical line (unit value) suggests significant outcome. Meta-regression analysis of the logRR of SSWI on the percentage of patients receiving BITA (B) and SITA (C) grafts. Size of circles corresponds to the number of patients in each study. BITA, Bilateral internal thoracic artery; $C I$, confidence interval; $d f$, degrees of freedom; $M-H$, Mantel-Haenszel; SITA, single internal thoracic artery.

\section{DISCUSSION}

The incidence of SWI after heart surgery varies from $0.9 \%$ to $20.0 \%$ across the available literature. ${ }^{24}$ In the present meta-analysis, it accounted for $3.82 \%$ in IGCS-treated patients and 3.98\% in controls. The present report highlights the potential role of gentamicin sponge implantation as an SWI prophylaxis during cardiac surgery. Unlike previous reports, ${ }^{25,26}$ this is the first meta-analysis to also include observational studies. The main findings of the present meta-analysis are as follows: (1) IGCS is universally associated with an approximately $40 \%$ SWI risk reduction, with results consistent between randomized and observational data; (2) in the overall analyses, this reduction is sustained for separate single end points: DSWI, SSWI, and mediastinitis; (3) mortality was not influenced by IGCS; and (4) the benefit provided by the gentamicin sponge might be attenuated when BITA is harvested.

SWIPE-1 questioned for the first time the longestablished efficacy of gentamicin sponge implantation for SWI prophylaxis. ${ }^{7}$ In a large 48 -center study, the authors demonstrated no reduction of SWI with gentamicinimpregnated collagen sponges in patients undergoing cardiac surgery, thus showing results contradictory to those from previous randomized and observational data. The authors explained the between-study discrepancies by the potential of onsite monitoring and source data verification with central adjudication of outcomes by an independent blinded committee and the multicenter design, and therefore higher ethnic and regional variability, in turn associated with diverse bacterial pathogens distribution (6.3\% of methicillin-resistant Staphylococcus aureus in the SWIPE-1 vs $0.0 \%$ in study by Friberg and colleagues $^{3,27}$ ). The latter may be of lesser importance in light of increasing methicillin resistance across coagulase-negative staphylococci strains and the majority of the pathogens generally susceptible to gentamicin. Concern remains regarding the high percentage of Gram-negative $\mathrm{G}(-)$ strains in the US trial obtained from microbial swabs compared with the remaining studies $(63 \%$ vs $0 \%-13 \%)$. This poses the question of when exactly the surgical site infection occurred because $G(-)$ flora should not be present in the air of the operating room and do not generally reside on the skin of the chest as do $\mathrm{G}(+)$ pathogens, and in particular coagulasenegative staphylococci. Therefore, it was argued ${ }^{26,28}$ that infections occurred postoperatively rather than in the perioperative period and to a lesser extent were dependent on the gentamicin prophylaxis. In a counter publication, Friberg and Bodin ${ }^{21}$ listed the flaws of the SWIPE-1 design, with a failure to follow manufacturer-advised sponge implantation protocol as their strongest argument. The differences in outcomes in the 2 studies were attributed to a longer exposure of gentamicin sponge to saline solution soon before implantation, thus resulting in different concentrations of gentamicin sulphate in the collagenbased matrix. The importance of this phenomenon was further corroborated by Lovering and Sunderland, ${ }^{29}$ who found in an in vitro study a mean loss of $6.7 \%$ of gentamicin concentration after 2 seconds of exposure to saline, 
increasing to $40.5 \%$ at 1 minute. Collagen sponge without gentamicin was further speculated to act as a culture medium and supported by the highest benefit of IGCS compared with placebo sponge in the study by Schimmer and colleagues. ${ }^{16}$ Quick deployment of the sponge with or without conditional short-dipping in the water solution, just to enable easier handling, therefore seems to play an essential role in the SWI prophylaxis; however, to date no single randomized study has addressed this concern.

The majority of the studies published so far have shown that the use of IGCS may significantly reduce the incidence of infectious complications after cardiac surgery. The current article is the first to demonstrate the consistent infection risk reduction in both a randomized and observational subset of patients; this is of particular importance because randomized trials tend to enroll highly selected groups of patients, thus compromising real-world scenario analyses. With the exception of SWIPE-1, which enrolled high-risk patients undergoing cardiac surgery (diabetes, BMI $>30 \mathrm{~kg} / \mathrm{m}^{2}$, or both), all RCTs were conducted in a mostly elective setting with the percentage of diabetic persons ranging from $18.3 \%$ to $32.4 \%$ and average BMI ranging from 26 to $28 \mathrm{~kg} / \mathrm{m}^{2}$. Our analysis demonstrated, apart from substantial reductions in DSWI and SSWI, a 33\% significant (RR, 0.67; 95\% CI, $0.49-0.92 ; P=.01)$ mediastinitis risk reduction with IGCS.

Another important finding of the current meta-analysis is a positive linear correlation between the $\operatorname{logRR}$ of SWI and the percentage of patients receiving a BITA graft, indicating the lesser benefit provided by the IGCS in this population. These findings are in line with previous reports demonstrating BITA to be an independent risk predictor for $\mathrm{DSWI}^{30,31}$; however, indicating for the first time that in case of patients' elevated baseline risk (diabetes, high BMI, chronic obstructive pulmonary disease, renal dysfunction) and BITA harvest, IGCS alone might not prevent infectious complications to an extent provided when SITA is used. Another potentially preventive measure must be taken in such patients, such as meticulous pinpoint hemostasis, rigid sternum fixation, avoidance of excessive use of bone wax, strict aseptic technique, and, above all, skeletonization of the internal thoracic arteries should be strongly preferred rather than pedicled harvest. ${ }^{32}$ We found no linear correlation between risk of SSWI alone and BITA harvesting; this finding might reflect the high potential of locally applied gentamicin to infiltrate the sternal fascia and subcutaneous tissue, unhindered by compromised blood circulation in the sternal region because of bilateral loss of the internal thoracic artery.

Gentamicin-collagen implants have been extensively tested outside the cardiothoracic surgery field and shown to decrease wound infections in other groups of patients undergoing surgical procedures, including open and endoscopic abdominal, vascular, and breast surgery. Reports are available on IGCS applied during surgical repair of pilonidal sinus, perianal abscess, inguinal hernia, and treatment of hidradenitis suppurativa. ${ }^{\text {E1-E19 }}$ In addition to gentamicin, other topical antibiotics have been tested in SWI prophylaxis with promising results, among them vancomycin and bacitracin. In a recent study by Lazar and colleagues, ${ }^{33}$ patients undergoing cardiac surgery and treated with topical vancomycin applied as a slurry to the cut edges of the sternum were less likely to develop SSWI and DSWI ( $0 \%$ vs $1.6 \%, P<.0001$ and $0 \%$ vs $0.7 \%, P=.005$, respectively) compared with a matched control group. Another study found a 6-fold reduction in the risk of mediastinitis after cardiac surgery in patients in whom bacitracin ointment was applied to the sternotomy incision after closure. ${ }^{34}$ As for the cost-effectiveness, Speir and colleagues ${ }^{35}$ report $\$ 62,773$ of additive costs for patients developing SWI after coronary artery bypass grafting. In our institution, the average estimated cost increases approximately 5 -fold from baseline, accounting for hospital stay, antibiotics, vacuum-assisted closure, and definitive surgical treatment. The introduction of IGCS in our department (Department of Cardiac Surgery, Dr Antoni Jurasz Memorial University Hospital, Bydgoszcz, Poland) (Figure E4) allowed for an approximately 5 -fold reduction in the incidence of SWIs only when implanted in high-risk patients $(0.6 \%$ SWI rate in 2012 [ $55 \%$ IGCS use] vs $2.53 \%$ SWI rate in 2005 [ $0 \%$ IGCS use]). Although the detailed pharmacoeconomic analysis is the subject of an ongoing investigation, its preliminary results demonstrate that one SWI quarterly would overweigh the cost of IGCSs implanted in all patients undergoing operation in this period.

\section{Study Limitations}

Several limitations to our meta-analysis should be acknowledged. First, the present analysis shares the limitations of the original studies included; therefore, the results were analyzed on the trial level and not on the patient level. Without individual patient data, we could not adjust for baseline risk factors and clinical characteristics. The criteria for patients' inclusion were broad across the studies, more closely reflecting current clinical practice, enrolling both high-risk and elective surgery cases. Potentially heterogeneous definitions of superficial wound infection might pose another limitation. Because of the substantial paucity of randomized data, observational data, both prospective and retrospective, also were included. As a consequence, the majority of the studies were retrospective in nature and thus are always subject to potential biases, that is, selection bias, with the surgeon implanting the gentamicin sponge in patients in whom the benefit with such prophylaxis was more probable (eg, obese or diabetic patients). On the other hand, observational studies were analyzed separately and using a random effect model; this 
approach ensures that any heterogeneity among the studies arising from differences in design, surgeon preferences, and patients' baseline clinical characteristics is identified. We noted no signs of inconsistency for the comparison between observational and randomized studies with the number of tests for subgroup differences. Despite these limitations, the consistency in magnitude and direction of the estimates and overall effect of IGCSs and the stability of the results in sensitivity analyses make the overall estimates justified and support the robustness of the conclusions.

\section{CONCLUSIONS}

IGCSs significantly reduce the risk of SWI after cardiac surgery, with evidence consistent in randomized and observational-level data. However, the extent of this benefit might be attenuated in patients receiving BITA grafts.

\section{Conflict of Interest Statement}

Authors have nothing to disclose with regard to commercial support.

\section{References}

1. Kreter B, Woods M. Antibiotic prophylaxis for cardiothoracic operations. Meta-analysis of thirty years of clinical trials. J Thorac Cardiovasc Surg. 1992;104:590-9.

2. Eklund AM, Valtonen M, Werkkala KA. Prophylaxis of sternal wound infections with gentamicin-collagen implant: randomized controlled study in cardiac surgery. J Hosp Infect. 2005;59:108-12.

3. Friberg O, Svedjeholm R, Soderquist B, Granfeldt H, Vikerfors T, Kallman J. Local gentamicin reduces sternal wound infections after cardiac surgery: a randomized controlled trial. Ann Thorac Surg. 2005;79:153-62.

4. Schersten H. Modified prophylaxis for preventing deep sternal wound infection after cardiac surgery. APMIS. 2007;115:1025-8.

5. Friberg O, Dahlin LG, Kallman J, Kihlstrom E, Soderquist B, Svedjeholm R. Collagen-gentamicin implant for prevention of sternal wound infection; long-term follow-up of effectiveness. Interact Cardiovasc Thorac Surg. 2009;9:454-8.

6. Raja SG. Local application of gentamicin-containing collagen implant in the prophylaxis and treatment of surgical site infection following cardiac surgery. Int J Surg. 2012;10(Suppl 1):S10-4.

7. Bennett-Guerrero E, Ferguson TB Jr, Lin M, Garg J, Mark DB, Scavo VA, et al. Effect of an implantable gentamicin-collagen sponge on sternal wound infections following cardiac surgery: a randomized trial. JAMA. 2010;304:755-62.

8. Liberati A, Altman DG, Tetzlaff J, Mulrow C, Gotzsche PC, Ioannidis JP, et al The PRISMA statement for reporting systematic reviews and meta-analyses of studies that evaluate healthcare interventions: explanation and elaboration. BMJ. 2009;339:b2700.

9. Lundh A, Gotzsche PC. Recommendations by Cochrane Review Groups for assessment of the risk of bias in studies. BMC Med Res Methodol. 2008;8:22.

10. Stang A. Critical evaluation of the Newcastle-Ottawa scale for the assessment of the quality of nonrandomized studies in meta-analyses. Eur J Epidemiol. 2010; 25:603-5.

11. Seeger P, Gabrielsson A. Applicability of the Cochran Q test and the F test for statistical analysis of dichotomous data for dependent samples. Psychol Bull. 1968;69:269-77.

12. Higgins JPT, Thompson SG, Deeks JJ, Altman DG. Measuring inconsistency in meta-analyses. BMJ. 2003;327:557-60.

13. Stijnen T, Hamza TH, Ozdemir P. Random effects meta-analysis of event outcome in the framework of the generalized linear mixed model with applications in sparse data. Stat Med. 2010;29:3046-67.

14. Dahlin LG. The Linköping experience-ups and downs. APMIS. 2007;115: 1029-31.

15. Leyh RG, Bartels C, Sievers HH. Adjuvant treatment of deep sternal wound infection with collagenous gentamycin. Ann Thorac Surg. 1999;68:1648-51.
16. Schimmer C, Ozkur M, Sinha B, Hain J, Gorski A, Hager B, et al. Gentamicin-collagen sponge reduces sternal wound complications after heart surgery: a controlled, prospectively randomized, double-blind study. J Thorac Cardiovasc Surg. 2012;143:194-200.

17. Benedetto U, Raja SG, Harefield Cardiac Outcomes Research Group. Scoring system to guide decision making for the use of gentamicin-impregnated collagen sponge to prevent deep sternal wound infection. J Thorac Cardiovasc Surg. 2014; 148:2390-6.e1.

18. Birgand G, Radu C, Alkhoder S, Al Attar N, Raffoul R, Dilly MP, et al. Does a gentamicin-impregnated collagen sponge reduce sternal wound infections in high-risk cardiac surgery patients? Interact Cardiovasc Thorac Surg. 2013;16: 134-41.

19. Canádyová J, Kurfirst V, Mokráček A. Use of gentamicin-collagen sponges prior to sternal closure may lower the risk of sternal wound infection: a single center experience. Kardiochirurgia i Torakochirurgia Polska. 2012;9: 415-9.

20. Cohen G, Fremes S, Sever J, Moussa F, Christakis GT, Goldman BS. Mitigation of sternal wound infection by application of a gentamicin impregnated collagen sponge at the time of sternal closure. CSCS Poster Session II, abstract 495. Presented at: Canadian Cardiovascular Congress 2010; October 23-26, 2010; Toronto, Ontario, Canada. Available at: http://www.pulsus.com/ccc2010/abs/395.htm.

21. Friberg O, Bodin L. Collagen gentamicin for prevention of sternal wound infection: effective or not? Thorac Cardiovasc Surg. 2013;61:185-93.

22. Madej T, Szlapka M, Neumann F, Plötze K, Matschke K, Waldow T. Retrosternal gentamicin-collagen sponge does not reduce the incidence of mediastinitis in cardiac surgery. J Cardiothorac Surg. 2013;8(Suppl 1):O116.

23. Popescu F, Rochon M, Raja S. Impact of gentamicin-collagen sponge (Collatamp) on the incidence of sternal wound infection in high risk cardiac surgery patients. J Cardiothorac Surg. 2013;8(Suppl 1):O123.

24. Ridderstolpe L, Gill H, Granfeldt H, Ahlfeldt H, Rutberg H. Superficial and deep sternal wound complications: incidence, risk factors and mortality. Eur J Cardiothorac Surg. 2001;20:1168-75.

25. Creanor S, Barton A, Marchbank A. Effectiveness of a gentamicin impregnated collagen sponge on reducing sternal wound infections following cardiac surgery: a meta-analysis of randomised controlled trials. Ann R Coll Surg Engl. 2012;94: 227-31.

26. Mavros MN, Mitsikostas PK, Alexiou VG, Peppas G, Falagas ME. Gentamicin collagen sponges for the prevention of sternal wound infection: a meta-analysis of randomized controlled trials. J Thorac Cardiovasc Surg. 2012; $144: 1235-40$.

27. Friberg O, Svedjeholm R, Kallman J, Soderquist B. Incidence, microbiological findings, and clinical presentation of sternal wound infections after cardiac surgery with and without local gentamicin prophylaxis. Eur J Clin Microbiol Infect Dis. 2007;26:91-7.

28. Friberg O, Svedjeholm R, Soderquist B. Treating sternal wound infections after cardiac surgery with an implantable gentamicin-collagen sponge. JAMA. 2010; 304:2123-4; author reply 2124.

29. Lovering AM, Sunderland J. Impact of soaking gentamicin-containing collagen implants on potential antimicrobial efficacy. Int J Surg. 2012;10(Suppl 1):S2-4.

30. Tavilla G, Kappetein AP, Braun J, Gopie J, Tjien AT, Dion RA. Long-term follow-up of coronary artery bypass grafting in three-vessel disease using exclusively pedicled bilateral internal thoracic and right gastroepiploic arteries. Ann Thorac Surg. 2004; 77:794-9.

31. Ura M, Sakata R, Nakayama Y, Arai Y. Bilateral pedicled internal thoracic artery grafting. Eur J Cardiothorac Surg. 2002;21:1015-9.

32. Sa MP, Ferraz PE, Escobar RR, Vasconcelos FP, Ferraz AA, Braile DM, et al. Skeletonized versus pedicled internal thoracic artery and risk of sternal wound infection after coronary bypass surgery: meta-analysis and meta-regression of 4817 patients. Interact Cardiovasc Thorac Surg. 2013;16:849-57.

33. Lazar HL, Ketchedjian A, Haime M, Karlson K, Cabral H. Topical vancomycin in combination with perioperative antibiotics and tight glycemic control helps to eliminate sternal wound infections. J Thorac Cardiovasc Surg. 2014;148: 1035-40.

34. MacIver RH, Stewart R, Frederiksen JW, Fullerton DA, Horvath KA. Topical application of bacitracin ointment is associated with decreased risk of mediastinitis after median sternotomy. Heart Surg Forum. 2006;9:E750-3.

35. Speir AM, Kasirajan V, Barnett SD, Fonner E Jr. Additive costs of postoperative complications for isolated coronary artery bypass grafting patients in Virginia. Ann Thorac Surg. 2009;88:40-6. 


\section{E-References}

E1. Costa Almeida CE, Reis L, Carvalho L, Costa Almeida CM. Collagen implant with gentamicin sulphate reduces surgical site infection in vascular surgery: a prospective cohort study. Int J Surg. 2014;12:1100-4.

E2. Chia CL, Shelat VG, Low W, George S, Rao J. The use of collatamp g, local gentamicin-collagen sponge, in reducing wound infection. Int Surg. 2014;99: $565-70$.

E3. de Bruin AF, Gosselink MP, van der Harst E. Local application of gentamicincontaining collagen implant in the prophylaxis of surgical site infection following gastrointestinal surgery. Int J Surg. 2012;10(Suppl 1):S21-7.

E4. Rutten HJ. Local application of gentamicin-containing collagen implant in the prophylaxis and treatment of surgical site infection. Int J Surg. 2012;10(Suppl 1):S15-20.

E5. de Bruin AF, Gosselink MP, Rutten HJ. Gentamicin sponge for infection prophylaxis in colorectal surgery. $N$ Engl J Med. 2010;363:2566; author reply 2566-7.

E6. Rutten HJ, Nijhuis PH. Prevention of wound infection in elective colorectal surgery by local application of a gentamicin-containing collagen sponge. Eur J Surg Suppl. 1997;31-5.

E7. Holzer B, Grussner U, Bruckner B, Houf M, Kiffner E, Schildberg FW, et al. Efficacy and tolerance of a new gentamicin collagen fleece (Septocoll) after surgical treatment of a pilonidal sinus. Colorectal Dis. 2003;5:222-7.

E8. Gruessner U, Clemens M, Pahlplatz PV, Sperling P, Witte J, Rosen HR, et al. Improvement of perineal wound healing by local administration of gentamicin-impregnated collagen fleeces after abdominoperineal excision of rectal cancer. Am J Surg. 2001;182:502-9.

E9. Nowacki MP, Rutkowski A, Oledzki J, Chwalinski M. Prospective, randomized trial examining the role of gentamycin-containing collagen sponge in the reduction of postoperative morbidity in rectal cancer patients: early results and surprising outcome at 3-year follow-up. Int J Colorectal Dis. 2005;20: 114-20.

E10. Szynglarewicz B, Ekiert M, Forgacz J, Matkowski R. Can gentamicincontaining collagen sponge be used for the protection against leakage following

low anterior resection with total mesorectal excision? Tech Coloproctol. 2014; 18:767-8.

E11. Szynglarewicz B, Matkowski R, Forgacz J, Pudelko M, Grzebieniak Z Anastomosis wrapping with gentamicin-containing collagen sponge in rectal cancer patients following sphincter-preserving total mesorectal excision without defunctioning stoma. Case Rep Clin Pract Rev. 2006;7:267e71.

E12. Brehant O, Sabbagh C, Lehert P, Dhahri A, Rebibo L, Regimbeau JM. The gentamicin-collagen sponge for surgical site infection prophylaxis in colorectal surgery: a prospective case-matched study of 606 cases. Int J Colorectal Dis. 2013;28:119-25.

E13. Bennett-Guerrero E, Pappas TN, Koltun WA, Fleshman JW, Lin M, Garg J, et al. Gentamicin-collagen sponge for infection prophylaxis in colorectal surgery. N Engl J Med. 2010;363:1038-49.

E14. Guzman Valdivia Gomez G, Guerrero TS, Lluck MC, Delgado FJ. Effectiveness of collagen-gentamicin implant for treatment of "dirty" abdominal wounds. World J Surg. 1999;23:123-7.

E15. Haase O, Raue W, Bohm B, Neuss H, Scharfenberg M, Schwenk W Subcutaneous gentamycin implant to reduce wound infections after loop-ileostomy closure: a randomized, double-blind, placebo-controlled trial. Dis Colon Rectum. 2005;48:2025-31.

E16. Vogel P, Lenz J. [Treatment of pilonidal sinus using excision and primary suture using a local, resorbable antibiotic carrier. Results of a prospective randomized study. Chirurg. 1992;63:748-53 [German].

E17. Rao MM, Zawislak W, Kennedy R, Gilliland R. A prospective randomised study comparing two treatment modalities for chronic pilonidal sinus with a 5-year follow-up. Int J Colorectal Dis. 2010;25:395-400.

E18. Yetim I, Ozkan OV, Dervisoglu A, Erzurumlu K, Canbolant E. Effect of gentamicin-absorbed collagen in wound healing in pilonidal sinus surgery: a prospective randomized study. J Int Med Res. 2010;38:1029-33.

E19. Yetim I, Ozkan OV, Dervisoglu A, Erzurumlu K, Canbolant E. Effect of loca gentamicin application on healing and wound infection in patients with modified radical mastectomy: a prospective randomized study. J Int Med Res. 2010;38:1442-7. 


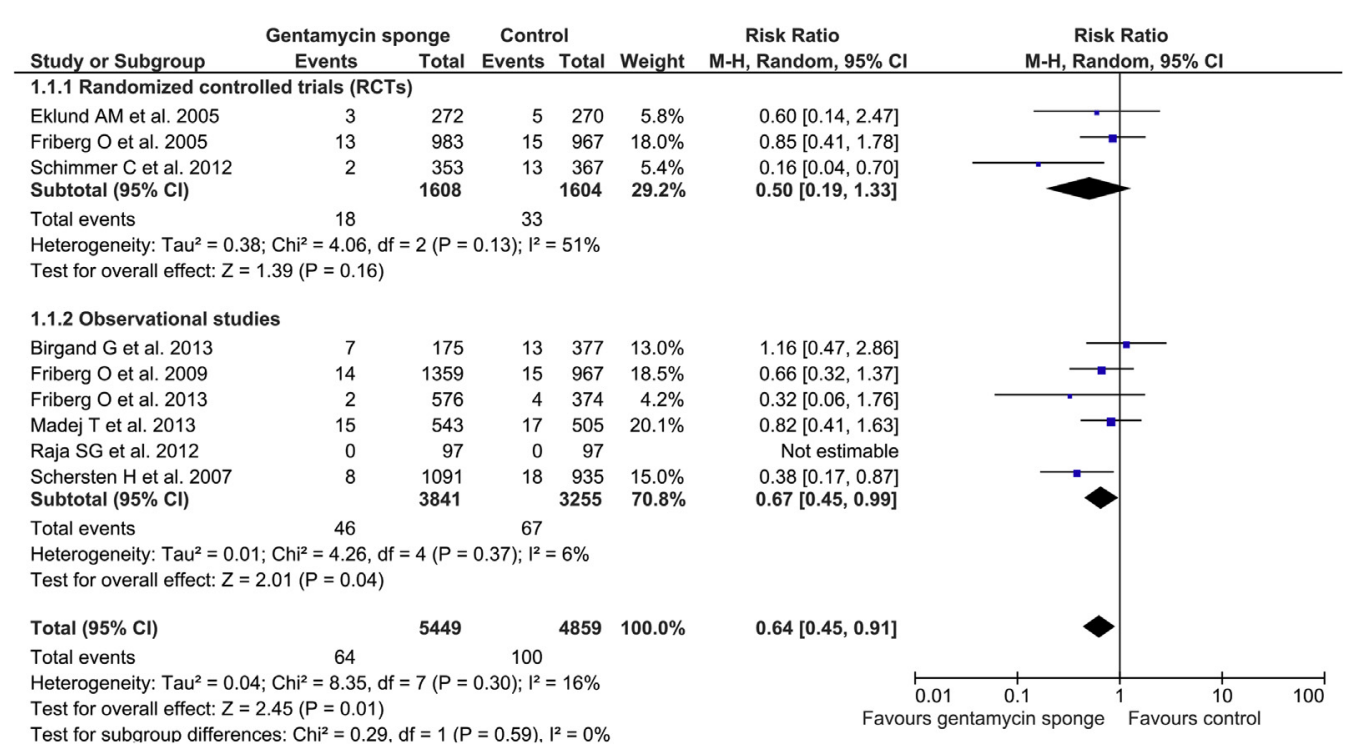

FIGURE E1. Summary analysis of mediastinitis. RRs and 95\% CIs. Size of squares is proportional to the statistical weight of each trial. Diamonds represent RR point estimates; horizontal lines represent CIs for given point estimate; positioning of both diamonds and squares (along with CIs) beyond the vertical line (unit value) suggests significant outcome. $C I$, Confidence interval; $d f$, degrees of freedom; $M$ - $H$, Mantel-Haenszel.

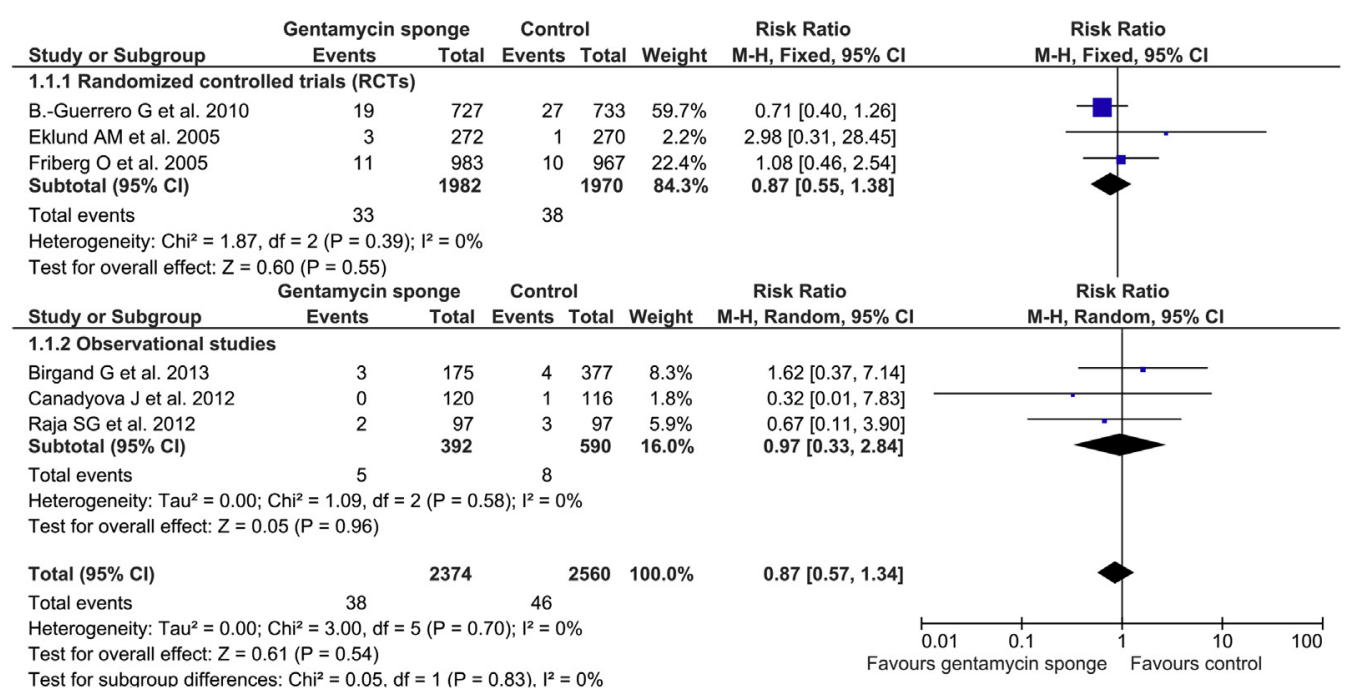

FIGURE E2. Summary analysis of mortality. RRs and $95 \%$ CIs. Size of squares is proportional to the statistical weight of each trial. Diamonds represent RR point estimates; horizontal lines represent CIs for given point estimate; positioning of both diamonds and squares (along with CIs) beyond the vertical line (unit value) suggests significant outcome. $C I$, Confidence interval; $d f$, degrees of freedom; $M-H$, Mantel-Haenszel. 


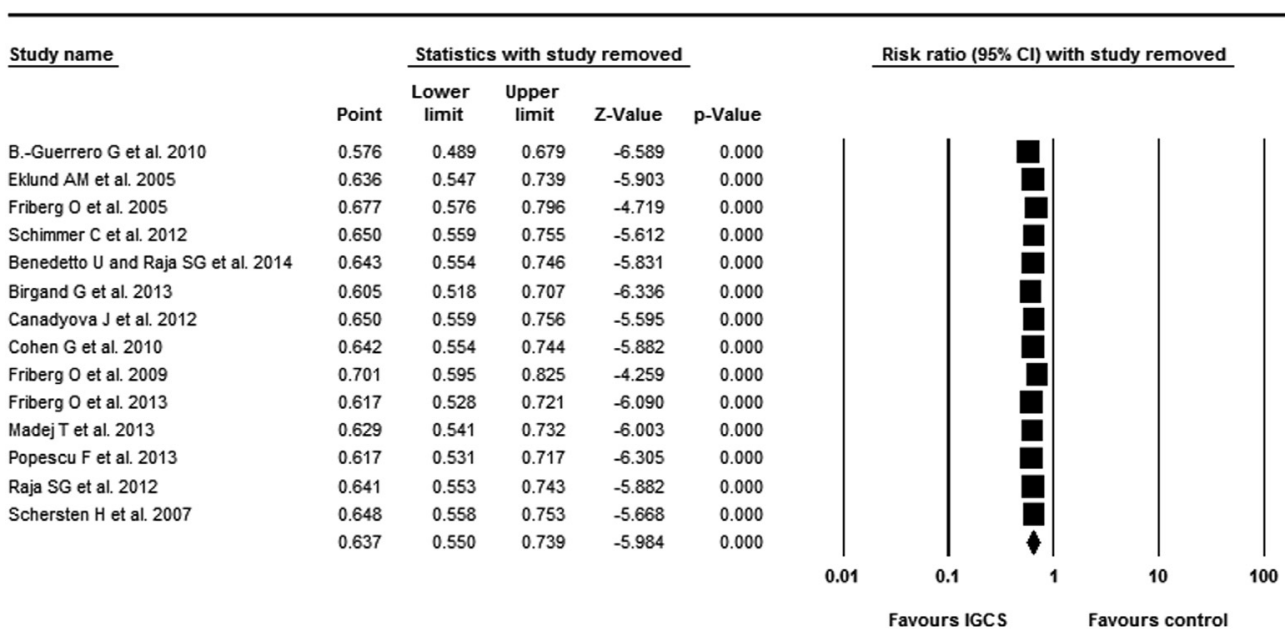

FIGURE E3. Sensitivity analysis for the primary end point conducted by deleting each single study at time and repeating the calculations. Analysis indicates no single study influenced the overall effect. $C I$, Confidence interval; IGCS, implantable gentamicin-collagen sponge.

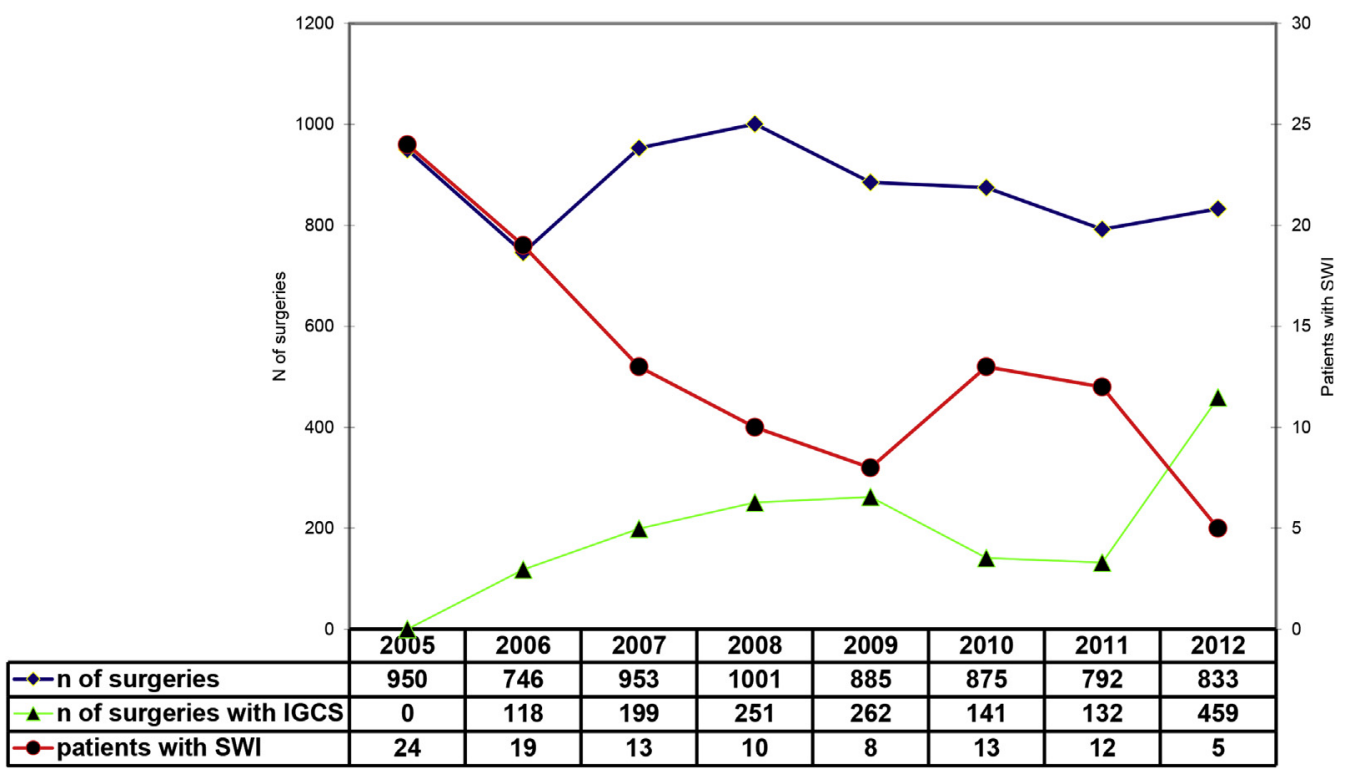

FIGURE E4. Yearly numbers of patients developing SWIs at the Department of Cardiac Surgery, Dr Antoni Jurasz Memorial University Hospital in Bydgoszcz plotted against the total number of surgeries and number of surgeries with IGCS implantation. IGCS, Implantable gentamicin-collagen sponge; $S W I$, sternal wound infection. 
TABLE E1. Newcastle-Ottawa scale of bias risk for observational studies

\begin{tabular}{|c|c|c|c|c|c|c|c|}
\hline \multirow[b]{2}{*}{ Study } & \multicolumn{3}{|c|}{ Adequacy of selection } & \multirow[b]{2}{*}{ Comparability } & \multicolumn{3}{|c|}{ Outcomes assessment } \\
\hline & $\begin{array}{c}\text { Representativeness } \\
\text { of the exposed } \\
\text { cohort }\end{array}$ & $\begin{array}{c}\begin{array}{c}\text { Selection } \\
\text { of the } \\
\text { nonexposed } \\
\text { cohort }\end{array} \\
\end{array}$ & $\begin{array}{c}\text { Ascertainment } \\
\text { of exposure }\end{array}$ & & $\begin{array}{l}\text { Assessment } \\
\text { of outcomes }\end{array}$ & $\begin{array}{c}\text { Follow-up } \\
\text { period long } \\
\text { enough for } \\
\text { outcome to } \\
\text { occur }\end{array}$ & $\begin{array}{c}\begin{array}{c}\text { Adequacy } \\
\text { of follow-up }\end{array} \\
\text { period among } \\
\text { cohorts } \\
\end{array}$ \\
\hline Benedetto and Raja $2014^{17}$ & $* *$ & $* *$ & $* * *$ & $*$ & $* * *$ & $*$ & $*$ \\
\hline Birgand and colleagues $2013^{18}$ & $* * *$ & $* * *$ & $* * *$ & $* *$ & $* * *$ & $* * *$ & $* * *$ \\
\hline Čanádyová and colleagues $2012^{19}$ & $* * *$ & $* * *$ & $* * *$ & $*$ & $* * *$ & $* * *$ & $* * *$ \\
\hline Cohen and colleagues $2010^{20}$ & $*$ & $*$ & $* *$ & $*$ & $* *$ & $*$ & $*$ \\
\hline Friberg and colleagues $2009^{5}$ & $* * *$ & $* * *$ & $* * *$ & $* *$ & $* * *$ & $* * *$ & $* * *$ \\
\hline Friberg and colleagues $2013^{21}$ & $* * *$ & $* * *$ & $* * *$ & $* *$ & $* * *$ & $* * *$ & $* * *$ \\
\hline Madej and colleagues $2013^{22}$ & $* * *$ & $* * *$ & $* *$ & $* *$ & $* * *$ & $* * *$ & $* * *$ \\
\hline Popescu and colleagues $2013^{23}$ & $* *$ & $* *$ & $*$ & $*$ & $* * *$ & $*$ & $* *$ \\
\hline Raja $2012^{6}$ & $* * *$ & $* * *$ & $* * *$ & $* *$ & $* * *$ & $* *$ & $* *$ \\
\hline Schersten, $2007^{4}$ & $*$ & $*$ & $* *$ & $*$ & $* * *$ & $*$ & $*$ \\
\hline
\end{tabular}

Asterisks are the star rating as per the Newcastle-Ottawa Scale; $* *$ and $* * *$ indicate highest ratings for these categories. 
PRISMA checklist

\begin{tabular}{ccc}
\hline Section/topic & No. Checklist item & Reported on page no. \\
\hline
\end{tabular}

TITLE

Title

ABSTRACT

Structured summary

\section{INTRODUCTION}

Rationale

Objectives

\section{METHODS}

Protocol and registration

Eligibility criteria

Information sources

Search

Study selection

Data-collection process

Data items

Risk of bias in individual studies

Summary measures

Synthesis of results

Risk of bias across studies

Additional analyses

\section{RESULTS}

Study selection

Study characteristics

Risk of bias within studies

Results of individual studies

Synthesis of results
Identify the report as a systematic review, meta-analysis, or both.

1

2

2 Provide a structured summary including, as applicable, background; objectives; data sources; study eligibility criteria, participants, and interventions; study appraisal and synthesis methods; results; limitations; conclusions and implications of key findings; systematic review registration number.

3 Describe the rationale for the review in the context of what is already known.

4 Provide an explicit statement of questions being addressed with reference to participants, interventions, comparisons, outcomes, and study design (PICOS).

5 Indicate if a review protocol exists, if and where it can be accessed (eg, Web address), and, if available, provide registration information including registration number.

6 Specify study characteristics (eg, PICOS, length of follow-up) and report characteristics (eg, years considered, language, publication status) used as criteria for eligibility, giving rationale.

7 Describe all information sources (eg, databases with dates of coverage, contact with study authors to identify additional studies) in the search and date last searched.

8 Present full electronic search strategy for at least 1 database, including any limits used, such that it could be repeated.

9 State the process for selecting studies (ie, screening, eligibility, included in systematic review, and, if applicable, included in the meta-analysis).

10 Describe method of data extraction from reports (eg, piloted forms, independently, in duplicate) and any processes for obtaining and confirming data from investigators.

11 List and define all variables for which data were sought (eg, PICOS, funding sources) and any assumptions and simplifications made.

12 Describe methods used for assessing risk of bias of individual studies (including specification of whether this was done at the study or outcome level) and how this information is to be used in any data synthesis.

13 State the principal summary measures (eg, RR, difference in means).

14 Describe the methods of handling data and combining results of studies, if done, including measures of consistency $\left(\mathrm{eg}, \mathrm{I}^{2}\right)$ for each meta-analysis.

15 Specify any assessment of risk of bias that may affect the cumulative evidence (eg, publication bias, selective reporting within studies).

16 Describe methods of additional analyses (eg, sensitivity or subgroup analyses, meta-regression), if done, indicating which were prespecified.

17 Give numbers of studies screened, assessed for eligibility, and included in the review, with reasons for exclusions at each stage, ideally with a flow diagram.

18 For each study, present characteristics for which data were extracted (eg, study size, PICOS, follow-up period) and provide the citations.

19 Present data on risk of bias of each study and, if available, any outcome level assessment (see item 12).

20 For all outcomes considered (benefits or harms), present for each study (a) simple summary data for each intervention group and (b) effect estimates and CIs, ideally with a forest plot.

21 Present results of each meta-analysis done, including CIs and measures of consistency.
4

NA

5

Appendix

5-6

6

5-6

6-7

6-7

5-7

6-7

7, Figure 1

7-8, Table 1

7-8, Appendix

8-11, Figures 2-4, Appendix

8-11, Figures 2-4, Appendix 
Continued

\begin{tabular}{|c|c|c|c|}
\hline Section/topic & No. & Checklist item & Reported on page no. \\
\hline Risk of bias across studies & 22 & Present results of any assessment of risk of bias across studies (see Item 15). & Appendix \\
\hline Additional analysis & 23 & $\begin{array}{l}\text { Give results of additional analyses, if done (eg, sensitivity or subgroup } \\
\text { analyses, meta-regression [see Item 16]). }\end{array}$ & 8-11, Figures 2-4, Appendix \\
\hline \multicolumn{4}{|l|}{ DISCUSSION } \\
\hline Summary of evidence & 24 & $\begin{array}{l}\text { Summarize the main findings, including the strength of evidence for each } \\
\text { main outcome; consider their relevance to key groups (eg, healthcare } \\
\text { providers, users, and policy makers). }\end{array}$ & $12-13$ \\
\hline Limitations & 25 & $\begin{array}{l}\text { Discuss limitations at study and outcome level (eg, risk of bias), and at } \\
\text { review level (eg, incomplete retrieval of identified research, reporting } \\
\text { bias). }\end{array}$ & $15-16$ \\
\hline Conclusions & 26 & $\begin{array}{l}\text { Provide a general interpretation of the results in the context of other } \\
\text { evidence and implications for future research. }\end{array}$ & $11-15$ \\
\hline \multicolumn{4}{|l|}{ FUNDING } \\
\hline Funding & 27 & $\begin{array}{l}\text { Describe sources of funding for the systematic review and other support (eg, } \\
\text { supply of data); role of funders for the systematic review. }\end{array}$ & NA \\
\hline
\end{tabular}

From: Moher D, Liberati A, Tetzlaff J, Altman DG; PRISMA Group. Preferred reporting items for systematic reviews and meta-analyses: the PRISMA statement. PLoS Med. 2009;6:e1000097. For more information, visit: www.prisma-statement.org. $C I$, Confidence interval; $N A$, not available; $R R$, risk ratio.

Full electronic search in MEDLINE database

\begin{tabular}{|c|c|c|}
\hline Search & Query & Items found \\
\hline 1 & Gentamycin OR Gentamicin AND sponge & 158 \\
\hline 2 & Gentamycin OR Gentamicin AND sponge AND cardiac & 13 \\
\hline 3 & Gentamycin OR Gentamicin AND sponge AND cardiovascular & 1 \\
\hline 4 & Gentamycin OR Gentamicin AND sponge AND cardiothoracic & 1 \\
\hline 5 & Gentamycin OR Gentamicin AND sponge AND heart & 4 \\
\hline 6 & Gentamycin OR Gentamicin AND sponge AND thoracic & 9 \\
\hline 7 & Gentamycin OR Gentamicin AND sponge AND bypass & 4 \\
\hline 8 & Gentamycin OR Gentamicin AND sponge AND by-pass & 0 \\
\hline 9 & Gentamycin OR Gentamicin AND sponge AND CABG & 1 \\
\hline 10 & Gentamycin OR Gentamicin AND sponge AND stern* & 12 \\
\hline 11 & Gentamycin OR Gentamicin AND sponge AND mediastin* & 3 \\
\hline 12 & Gentamycin OR Gentamicin AND implant* & 742 \\
\hline 13 & Gentamycin OR Gentamicin AND implant* AND cardiac & 63 \\
\hline 14 & Gentamycin OR Gentamicin AND implant* AND cardiovascular & 42 \\
\hline 15 & Gentamycin OR Gentamicin AND implant* AND cardiothoracic & 6 \\
\hline 16 & Gentamycin OR Gentamicin AND implant* AND heart & 48 \\
\hline 17 & Gentamycin OR Gentamicin AND implant* AND thoracic & 19 \\
\hline 18 & Gentamycin OR Gentamicin AND implant* AND bypass & 12 \\
\hline 19 & Gentamycin OR Gentamicin AND implant* AND bypass & 0 \\
\hline 20 & Gentamycin OR Gentamicin AND implant* AND CABG & 2 \\
\hline 21 & Gentamycin OR Gentamicin AND implant* AND stern* & 16 \\
\hline 22 & Gentamycin OR Gentamicin AND implant* AND mediastin* & 6 \\
\hline 23 & Gentamycin OR Gentamicin AND topical & 894 \\
\hline 24 & Gentamycin OR Gentamicin AND topical AND cardiac & 14 \\
\hline 25 & Gentamycin OR Gentamicin AND topical AND cardiovascular & 13 \\
\hline 26 & Gentamycin OR Gentamicin AND topical AND cardiothoracic & 2 \\
\hline 27 & Gentamycin OR Gentamicin AND topical AND heart & 9 \\
\hline 28 & Gentamycin OR Gentamicin AND topical AND thoracic & 8 \\
\hline 29 & Gentamycin OR Gentamicin AND topical AND bypass & 0 \\
\hline 30 & Gentamycin OR Gentamicin AND topical AND bypass & 0 \\
\hline 31 & Gentamycin OR Gentamicin AND topical AND CABG & 0 \\
\hline 32 & Gentamycin OR Gentamicin AND topical AND stern* & 8 \\
\hline 33 & Gentamycin OR Gentamicin AND topical AND mediastin* & 6 \\
\hline
\end{tabular}

$C A B G$, Coronary artery bypass grafting. 